\title{
Self-reported daily walking time in COPD: relationship with relevant clinical and functional characteristics
}

Maria A Ramon, ${ }^{1-3}$

Cristina Esquinas,' Miriam

Barrecheguren,' Eulogio

Pleguezuelos, ${ }^{4,5}$ Jesús

Molina, ${ }^{6}$ José A Quintano, ${ }^{7}$

Miguel Roman-Rodríguez, ${ }^{8}$

Karlos Naberan, ${ }^{9}$ Carl

Llor, ${ }^{10}$ Carlos Roncero, ${ }^{11-14}$

Marc Miravitlles 1,3

'Department of Pneumology, Vall d'Hebron University Hospital, ${ }^{2}$ Faculty of Medicine, Autonomous University of Barcelona, ${ }^{3}$ Biomedical Research Networking Center Consortium of Respiratory Diseases (CIBERES), ${ }^{4}$ Physical Medicine and Rehabilitation Department, Mataró Hospital,

${ }^{5}$ TecnoCampus, College of Health

Sciences, University of Pompeu Fabra Mataró-Maresme, Barcelona, ${ }^{6}$ Francia Health Center, Dirección Asistencial Oeste, Madrid, ${ }^{7}$ Lucena Health Center I, Lucena, Córdoba, ${ }^{8}$ Son Pisà Primary Health Care Center, Palma de Mallorca, ${ }^{9} \mathrm{Campo}$ de Belchite Health Center, Zaragoza, ${ }^{10}$ Primary Care Centre Via Roma, "Addiction and Dual Diagnosis Unit, Psychiatry Service, Vall d'Hebron University Hospital, '2Barcelona Public Health Agency (ASPB), Barcelona, ${ }^{13}$ Biomedical Research Networking Center Consortium of Mental Health (CIBERSAM), Madrid, ${ }^{14}$ Department of Psychiatry, Autonomous University of Barcelona, Barcelona, Spain

Correspondence: Marc Miravitlles Department of Pneumology, Hospital Universitari Vall d'Hebron, Passeig Vall d'Hebron II9-129, 08035

Barcelona, Spain

Tel +34932746I 07

Fax +34932746208

Email mmiravitlles@vhebron.net
This article was published in the following Dove Press journal:

International Journal of COPD

13 April 2017

Number of times this article has been viewed

Background: Quantifying physical activity in chronic obstructive pulmonary disease (COPD) is important as physical inactivity is related to poor health outcomes. This study analyzed the relationship between patients' self-reported daily walking time and relevant characteristics related to COPD severity.

Methods: Pooled analysis was performed on data from four observational studies on which daily walking time was gathered from a personal interview. Patients were classified as physically inactive if walking time was $<30 \mathrm{~min} /$ day. Walking times were described and compared according to several markers of disease severity.

Results: The mean daily walking time of 5,969 patients was 66 (standard deviation [SD] 47) min/day; 893 (15\%) patients were inactive. A linear dose-response relationship was observed between walking time and the modified Medical Research Council (mMRC) dyspnea score, admissions, COPD assessment test (CAT), body mass index, airway obstruction, dyspnea, exacerbation (BODEx) index, and Charlson index $(P<0.001)$. Daily walking times were lower in patients classified as Global Initiative for Chronic Obstructive Lung Disease (GOLD) B and $\mathrm{D}(P<0.001)$. Often, inactive patients had $\mathrm{mMRC}$ or Charlson index $>3$, post-bronchodilator forced expiratory volume in the first second $<30 \%$ predicted, at least one hospitalization for COPD, classified as GOLD B or D, BODEx $>4$, and CAT score $>30$.

Conclusion: Lower self-reported walking times are related to worse markers of disease severity in COPD.

Keywords: COPD, physical activity, symptoms

\section{Introduction}

COPD has several significant extra-pulmonary effects, such as skeletal muscle impairment and exercise intolerance, which have an important effect on the daily life activities of patients with this disease. ${ }^{1,2}$ This observation is consistent with the fact that patients with COPD have significantly lower levels of physical activity compared with healthy controls. ${ }^{3}$ Moreover, reduced levels of physical activity have been found to be related to an increased risk of hospital admissions and mortality in COPD. ${ }^{4-6}$ Therefore, quantification of physical activity is of great value in these patients.

It has recently been recommended that evaluation of the level of physical activity in COPD should be carried out using movement sensors, which constitute portable equipment that quantify the activity performed by an individual during a given period of time. $^{7}$ The physical activity of patients with COPD can also be assessed using validated questionnaires, which are less expensive and easier to use than movement sensors, but most of these questionnaires are still time-consuming. ${ }^{7,8}$ Thus, these instruments 
are not feasible in clinical practice. Nonetheless, national and international guidelines on the management of COPD recommend evaluation and, if necessary, interventions to promote physical activity in these patients which has led to the need for less sophisticated tools to determine the daily physical activity of patients with COPD. ${ }^{1-9}$

The American College of Sports Medicine recommends that older adults should perform at least $30 \mathrm{~min}$ of physical activity of moderate intensity, such as walking, most days of the week in order to maintain or develop fitness. ${ }^{10}$ Thus, individuals not fulfilling this recommendation are currently considered to be physically inactive. Self-reporting of walking time by patients would allow easy data collection at all levels of care and could help clinicians to better understand the impact of the disease on the patients' daily life in order to identify subjects at risk of a sedentary lifestyle and to select candidates for an intervention to promote physical activity.

The present study was aimed at investigating the usefulness of self-reported walking time to identify patients with COPD at high risk of inactivity. It reported and compared the self-reported daily walking times of a large sample of patients with COPD from both primary care and specialized respiratory departments according to the clinical characteristics related to disease severity, such as the degree of airflow limitation, the grade of dyspnea, and different multidimensional scoring systems.

\section{Methods}

\section{Study design, participants, and ethics}

A pooled analysis of individual-level data from four multicenter, cross-sectional, observational studies described elsewhere was performed: the INSEPOC (Spanish acronym for "Impact of socio-economic status on quality of life of COPD patients"), ${ }^{11}$ the FYCEPOC (Spanish acronym for "Phenotypes and quality of life of patients with COPD"), ${ }^{12}$ the NEREA (Spanish acronym for "New severity scale for COPD in primary care"), ${ }^{13}$ and the DEPREPOC (Spanish acronym for "Depression in patients with COPD" $)^{14}$ studies. In brief, stable COPD patients were recruited from both primary care and pulmonology departments. All the studies included individuals aged $\geq 40$ years, smokers or ex-smokers of at least 10 pack-years with spirometrically confirmed COPD (post-bronchodilator forced expiratory volume in the first second $\left[\mathrm{FEV}_{1}\right] /$ forced vital capacity $\left.<0.7\right)$. All the studies were approved by the Research and Ethics Committee of the Hospital Clinic (Barcelona, Spain), and written informed consent was obtained from each participant.

\section{Measurements}

Physical activity defined as patients' self-reported daily walking time was collected in a personal interview, and patients were classified into three categories of physical activity: low (self-reported walking time $<30 \mathrm{~min} /$ day), moderate (self-reported walking time of 30-60 min/day), and high (self-reported walking time $>60 \mathrm{~min} /$ day). Self-reported daily walking time both as a continuous and as a categorical variable was used in the analysis.

Sociodemographic, clinical, and functional data as well as the number of exacerbations and hospital admissions due to COPD in the previous year were collected from all of the patients studied. Forced spirometry was conducted before and after a bronchodilator test, and self-reported comorbid conditions were calculated according to the Charlson comorbidity index. ${ }^{15}$ Dyspnea was assessed using the modified Medical Research Council (mMRC) dyspnea scale $^{16}$ in three studies, ${ }^{12-14}$ and the COPD assessment test (CAT) score ${ }^{17}$ was available in two of the studies. ${ }^{12-14}$ Higher values in the CAT questionnaire indicate worse health status. ${ }^{17}$

Patients were classified according to the $\mathrm{FEV}_{1}$ as mild, moderate, severe, and very severe following the European Respiratory Society and the American Thoracic Society (ERS/ATS) criteria ${ }^{18}$ as well as the current Global Initiative for Chronic Obstructive Lung Disease (GOLD) A to D groups, using the highest mMRC or CAT thresholds. ${ }^{1}$ According to this classification, patients in GOLD B and D have higher symptom scores in common. The BODEx (body mass index, airway obstruction, dyspnea, and exacerbation) index, with which higher values indicate poor prognosis, was also calculated accordingly. ${ }^{19}$

\section{Statistical analysis}

Descriptive data are presented as number and percentage, and the mean and standard deviation (SD), or the median and 25 th or 75 th percentiles, as appropriate. Self-reported walking time, both as a continuous and as a categorical variable, was described and compared according to various disease severity markers. A test for trends was calculated by using various disease severity markers as an ordinal variable in a linear regression model and the self-reported walking time as a continuous outcome. Finally, bivariate logistic regression models were used to calculate pooled odds ratios (ORs) for self-reported walking time $<30 \mathrm{~min} /$ day according to disease severity markers. The analyses were performed by using Stata 12.1 (StataCorp, College Station, TX, USA). 


\section{Results}

Information related to the self-reported daily walking time was available in 5,969 patients. Table 1 presents the main clinical and functional characteristics of the pooled sample. Most of the patients studied were males (86\%) with a mean age of 67.5 (SD 9.6) years and a $\mathrm{FEV}_{1}$ of $50.7 \%$ (17.2) predicted. Regarding GOLD groups, the majority of patients (73\%) belonged to the GOLD D group.

Patients reported a mean daily walking time of 66 (SD 47) min/day, with $893(15.0 \%)$ patients being classified as physically inactive (self-reported daily walking time $<30 \mathrm{~min} /$ day) (Figure 1). Table 2 shows the selfreported daily walking times according to different characteristics related to disease severity.

A linear dose-response relationship was observed between the self-reported daily walking time as a continuous variable and the mMRC dyspnea score, COPD admissions within the previous year, the CAT score, the BODEx index, and the Charlson index $(P<0.001)$. That is, lower walking times were associated with worse markers of disease severity. Selfreported daily walking times were lower in patients classified as GOLD B and D than those in the GOLD A and C groups $(P<0.001)$. There was no dose-response relationship between self-reported daily walking time and $\mathrm{FEV}_{1}$ levels $(P=0.080)$ (Figure 2). Figure 3 shows the distribution of patients with low, moderate, and high self-reported daily walking times according to different markers of disease severity. Low physical activity was more frequent in patients with severe dyspnea ( $m M R C ~ \geq 3$ ), more than two COPD admissions in the previous 12 months, CAT score $>30$, and BODEx index $>4$ points.

Table 3 shows the ORs for lower self-reported daily walking times according to different COPD severity factors. Patients at a higher risk of low self-reported daily physical activity were those with mMRC or Charlson index $>3$, a $\mathrm{FEV}_{1}<30 \%$ predicted, at least one COPD admission in the previous year, classified as GOLD B or D, a BODEx $>4$, and CAT score $>30$.

\section{Discussion}

The present study investigated the relationship between self-reported daily walking time and relevant characteristics related to COPD severity in a large sample of patients

Table I Sociodemographic, clinical, and functional characteristics of the patients included in different studies

\begin{tabular}{|c|c|c|c|c|c|}
\hline Parameter & All $n=5,969$ & INSEPOC $n=2,026$ & FYCEPOC $n=2,735$ & NEREA $n=622$ & DEPREPOC $\mathrm{n}=586$ \\
\hline Age (years) & $67.5(9.6)$ & $67.4(9.6)$ & $67.0(9.6)$ & $68.8(10.0)$ & $68.8(9.1)$ \\
\hline Sex (male) & $5,145(86.3)$ & I,831 (90.4) & $2,273(83.1)$ & $546(87.9)$ & $495(85.1)$ \\
\hline Active smokers & $1,394(23.4)$ & $534(26.5)$ & $616(23.7)$ & $126(20.7)$ & $118(20.31)$ \\
\hline Body mass index $\left(\mathrm{kg} / \mathrm{m}^{2}\right)$ & $27.8(4.4)$ & $27.9(4.4)$ & $27.7(4.3)$ & $27.7(4.1)$ & $27.5(4.6)$ \\
\hline Comorbidities (Charlson index) & $2(I-3)$ & $2(1-3)$ & $2(I-2)$ & $2(I-3)$ & $2(I-3)$ \\
\hline \multicolumn{6}{|l|}{$\mathrm{mMRC}(\mathrm{n}=3,937)$} \\
\hline 0 & $246(6.3)$ & - & $170(6.2)$ & $51(8.3)$ & $25(4.2)$ \\
\hline 1 & $1533(38.9)$ & - & $1,027(37.5)$ & $299(48.4)$ & $207(35.4)$ \\
\hline 2 & $1373(34.9)$ & - & $987(36.1)$ & $159(25.8)$ & $227(38.8)$ \\
\hline 3 & $665(16.9)$ & - & $459(16.8)$ & $88(14.3)$ & 118 (20.2) \\
\hline 4 & $120(3.0)$ & - & $92(3.4)$ & $20(3.2)$ & $8(1.4)$ \\
\hline Ambulatory COPD exacerbation" & I $(0-2)$ & $2(I-3)$ & I $(0-2)$ & $I(I-2)$ & $2(I-3)$ \\
\hline COPD admissions ${ }^{\pi}$ & $0(0-1)$ & $0(0-1)$ & $0(0-1)$ & $0(0-1)$ & I (0-2) \\
\hline FEV (\% predicted) & $50.7(17.2)$ & $47.7(16.2)$ & $51.9(17.9)$ & $52.8(15.9)$ & $52.8(16.7)$ \\
\hline \multicolumn{6}{|l|}{ FEV, levels } \\
\hline$\geqq 80 \%$ predicted & $319(5.3)$ & 7I (3.5) & $20 I(7.4)$ & $18(2.9)$ & $29(4.9)$ \\
\hline$\geqq 50 \%$ and $<80 \%$ predicted & $2,634(44.1)$ & $784(38.7)$ & $1,225(44.8)$ & $325(52.3)$ & $300(5 \mathrm{I} .2)$ \\
\hline$\geqq 30 \%$ and $<50 \%$ predicted & $2,315(38.8)$ & $878(43.3)$ & $1,002(36.6)$ & $226(36.3)$ & $209(35.7)$ \\
\hline$<30 \%$ predicted & $701(11.7)$ & $293(14.5)$ & $307(11.2)$ & $53(8.5)$ & $48(8.2)$ \\
\hline \multicolumn{6}{|l|}{ GOLD groups $(n=3,209)$} \\
\hline A & $156(4.9)$ & - & $|4|(5.3)$ & - & $15(2.8)$ \\
\hline$B$ & $542(16.9)$ & - & $491(18.3)$ & - & $5 \mathrm{I}(9.7)$ \\
\hline C & $168(5.2)$ & - & $146(5.5)$ & - & $22(4.2)$ \\
\hline $\mathrm{D}$ & $2,343(73.0)$ & - & $1,903(70.9)$ & - & $440(83.3)$ \\
\hline BODEx index $(n=3,765)$ & $2(1-4)$ & - & $2(I-4)$ & $2(I-4)$ & $3(2-4)$ \\
\hline CAT $(n=3,262)$ & $20.0(8.3)$ & - & $19.2(8.2)$ & - & $21.2(8.1)$ \\
\hline
\end{tabular}

Notes: Data are presented as $\mathrm{n}(\%)$, mean (SD), or median (percentile 25-p75). "Some variables have missing values: 27 in age, 9 in sex, 169 in active smoker, 54 in body mass index, 165 in ambulatory COPD exacerbation, and I35 in COPD admissions. "Number of events in the previous 12 months.

Abbreviations: BODEx, body mass index, airway obstruction, dyspnea, exacerbation; CAT, COPD assessment test; DEPREPOC, Depression in patients with COPD; $\mathrm{FEV}_{1}$, forced expiratory volume in the first second; FYCEPOC, Phenotypes and quality of life of patients with COPD; GOLD, Global Initiative for Chronic Obstructive Lung Disease; INSEPOC, Impact of socio-economic status on quality of life of COPD patients; mMRC, modified Medical Research Council dyspnea score; NEREA, New severity scale for COPD in primary care; SD, standard deviation. 


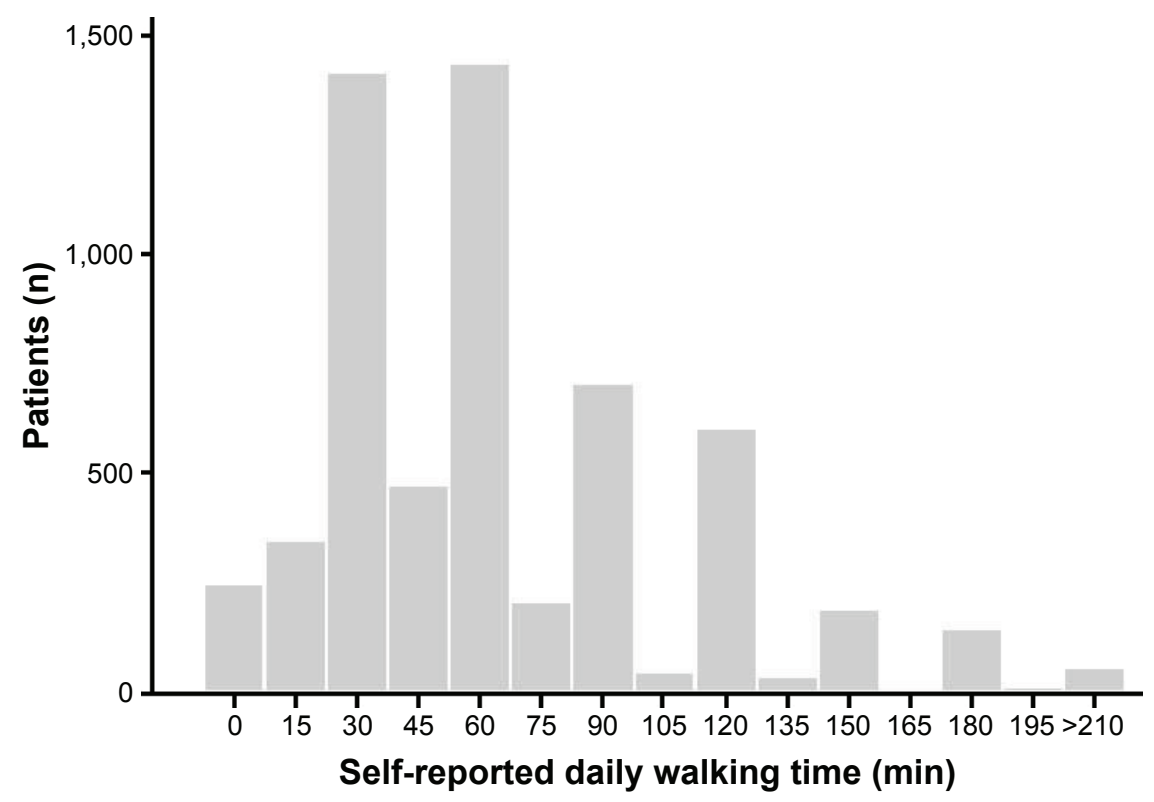

Figure I Distribution of self-reported daily walking times in the 5,969 COPD study patients. Abbreviation: COPD, chronic obstructive pulmonary disease.

Table 2 Self-reported daily walking time according to different characteristics related to disease severity

\begin{tabular}{|c|c|c|c|c|}
\hline \multirow[t]{2}{*}{ Characteristics } & \multirow[t]{2}{*}{ Patients (n) } & \multicolumn{3}{|c|}{ Self-reported daily walking time ( $\mathrm{min} /$ day) } \\
\hline & & Mean (SD) & $<30 \mathrm{~min} /$ day n (\%) & $\geq 30 \mathrm{~min} /$ day $\mathrm{n}(\%)$ \\
\hline \multicolumn{5}{|l|}{ mMRC dyspnea score } \\
\hline $0-1$ & 1,779 & $73(46)$ & $161(9.1)$ & I,618 (90.9) \\
\hline 2 & $\mathrm{I}, 373$ & $61(42)$ & $181(13.2)$ & I, $192(86.8)$ \\
\hline 3 & 665 & $48(40)$ & $187(28.1)$ & $478(71.9)$ \\
\hline 4 & 120 & $25(29)$ & $77(64.2)$ & $43(35.8)$ \\
\hline \multicolumn{5}{|l|}{ FEV, levels } \\
\hline$\geqq 80 \%$ predicted & 319 & $64(47)$ & $48(15.1)$ & $271(84.9)$ \\
\hline$\geqq 50 \%$ and $<80 \%$ predicted & 2,634 & $68(47)$ & $306(11.6)$ & $2,328(88.4)$ \\
\hline$\geqq 30 \%$ and $<50 \%$ predicted & 2,315 & $64(46)$ & $381(16.4)$ & $1,934(83.6)$ \\
\hline$<30 \%$ predicted & 701 & $60(47)$ & $158(22.5)$ & $543(77.5)$ \\
\hline \multicolumn{5}{|l|}{ COPD admissions $\pi$} \\
\hline 0 & 3,457 & $7 \mid(48)$ & 398 (II.4) & $3,063(88.6)$ \\
\hline I & 1,288 & $63(46)$ & $198(15.4)$ & I,090 (84.6) \\
\hline 2 & 598 & $55(44)$ & $144(24.1)$ & $454(75.9)$ \\
\hline$>2$ & 491 & $49(4 I)$ & $142(28.9)$ & 349 (7I.I) \\
\hline \multicolumn{5}{|l|}{ CAT } \\
\hline$<10$ & 522 & $76(48)$ & $4 \mathrm{I}(7.8)$ & $481(92.2)$ \\
\hline $10-20$ & 1,212 & $66(43)$ & $148(12.2)$ & $\mathrm{I}, 064(87.8)$ \\
\hline $20-30$ & $\mathrm{I}, 224$ & $56(39)$ & 239 (19.5) & $985(80.5)$ \\
\hline$>30$ & 304 & $44(38)$ & $94(30.9)$ & $210(69.1)$ \\
\hline \multicolumn{5}{|l|}{ GOLD groups } \\
\hline A & 156 & $80(49)$ & $8(5.1)$ & I 48 (94.9) \\
\hline B & 542 & $64(42)$ & $66(12.2)$ & $476(87.8)$ \\
\hline C & 168 & $79(50)$ & $13(7.7)$ & $155(92.3)$ \\
\hline $\mathrm{D}$ & 2,343 & $58(42)$ & 431 (18.4) & $1,912(81.6)$ \\
\hline \multicolumn{5}{|l|}{ BODEx index } \\
\hline $0-1$ & 1,082 & $70(44)$ & $87(8.0)$ & $995(92.0)$ \\
\hline 2 & 821 & $67(45)$ & $103(12.6)$ & $718(87.4)$ \\
\hline $3-4$ & $\mathrm{I}, 180$ & $61(45)$ & $186(15.8)$ & 994 (84.2) \\
\hline$>4$ & 682 & $48(4 I)$ & 209 (30.7) & $473(69.3)$ \\
\hline \multicolumn{5}{|l|}{ Charlson index } \\
\hline I & 2,302 & $69(48)$ & $283(12.3)$ & 2,019 (87.7) \\
\hline 2 & 2,045 & $67(46)$ & $283(13.8)$ & I,762 (86.2) \\
\hline 3 & $\mathrm{I}, 080$ & $60(44)$ & $185(17.1)$ & $895(82.9)$ \\
\hline$\geqq 4$ & 542 & $55(47)$ & 142 (26.2) & $400(73.8)$ \\
\hline
\end{tabular}

Note: "Number of events in the previous 12 months.

Abbreviations: BODEx, body mass index, airway obstruction, dyspnea, exacerbation; CAT, COPD assessment test; COPD, chronic obstructive pulmonary disease; FEV, forced expiratory volume in the first second; GOLD, Global Initiative for Chronic Obstructive Lung Disease; mMRC, modified Medical Research Council dyspnea scale; SD, standard deviation. 
A

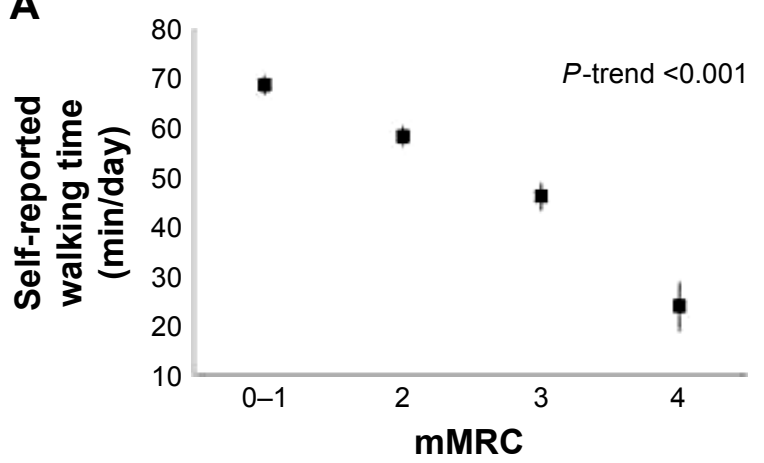

C

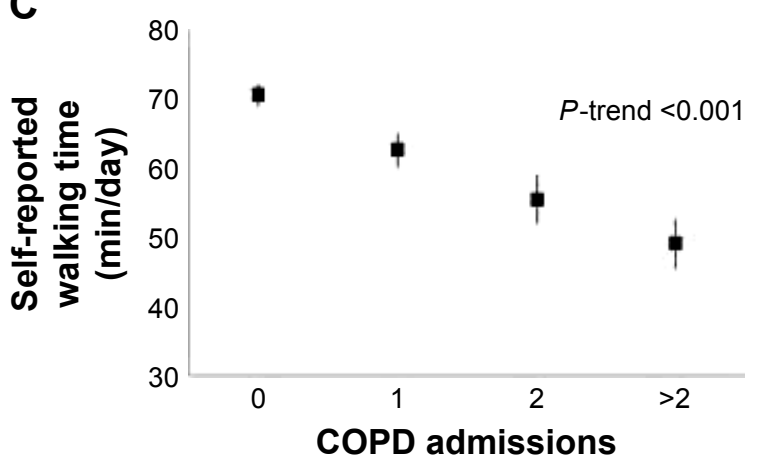

E

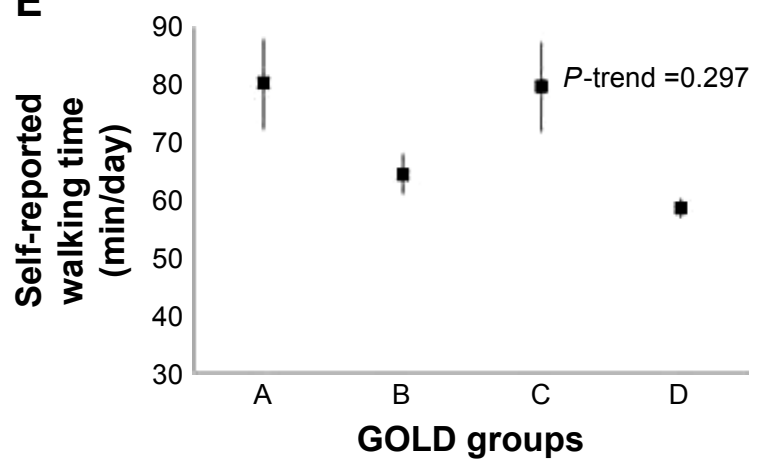

G

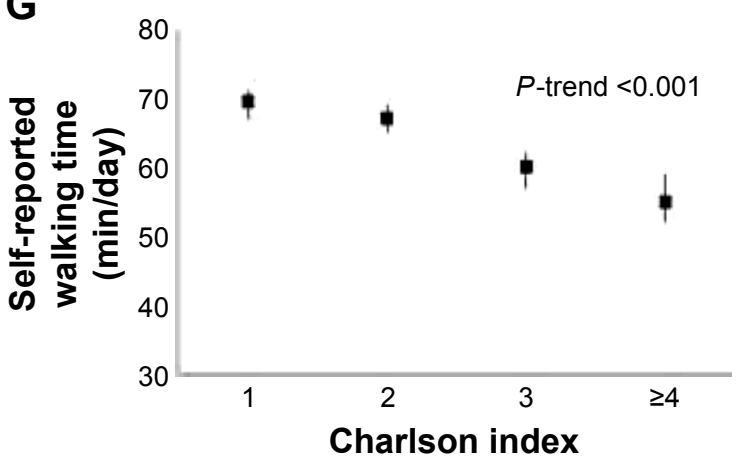

B

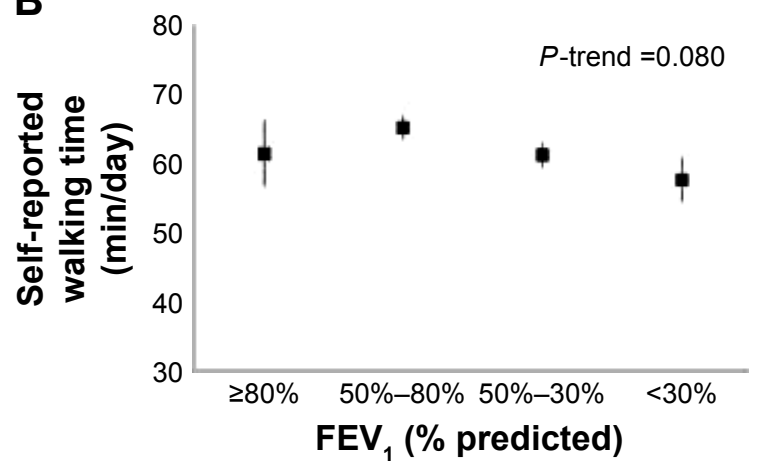

D

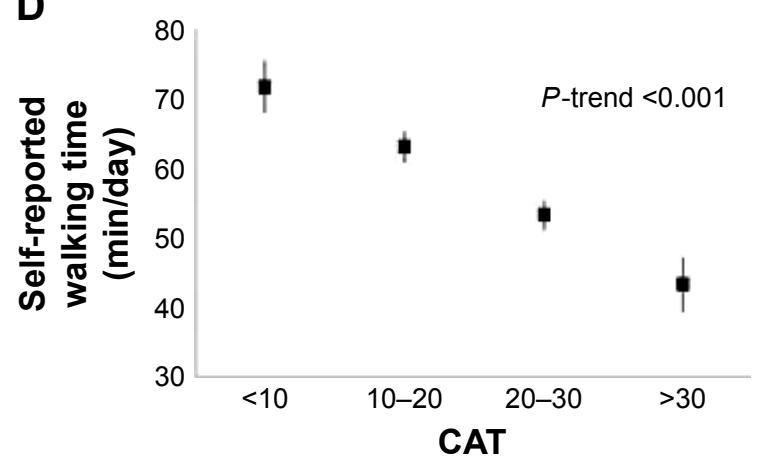

$\mathbf{F}$

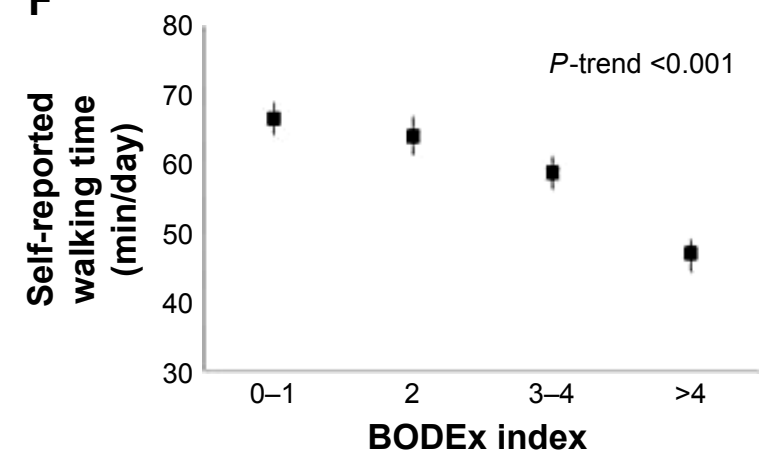

Charison index

Figure 2 Self-reported daily walking times according to (A) mMRC, (B) FEV,\% predicted, (C) COPD admissions in the previous I2 months, (D) CAT, (E) GOLD A-D groups, (F) BODEx index, and (G) Charlson index of comorbidities. Data are presented as mean values with $95 \%$ confidence intervals.

Abbreviations: BODEx, body mass index, airway obstruction, dyspnea, exacerbation; CAT, COPD assessment test; COPD, chronic obstructive pulmonary disease; FEV, forced expiratory volume in the first second; GOLD, Global Initiative for Chronic Obstructive Lung Disease; mMRC, modified Medical Research Council dyspnea scale.

with COPD. The main findings were that patients reporting lower walking times were those with more dyspnea, more comorbidities, higher BODEx index, patients classified as GOLD B or D and with previous hospitalizations due to
COPD exacerbation. Furthermore, airflow limitation was poorly related to self-reported daily walking time.

Most patients with COPD spend significantly less time walking in daily life than healthy elderly subjects. ${ }^{3,20}$ 
A

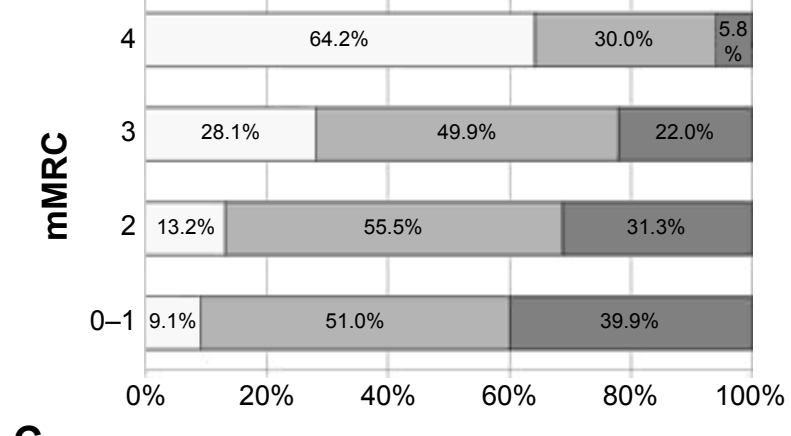

C

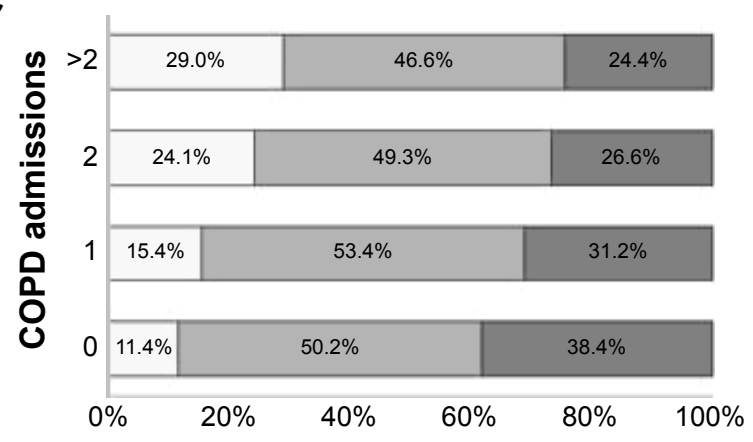

E

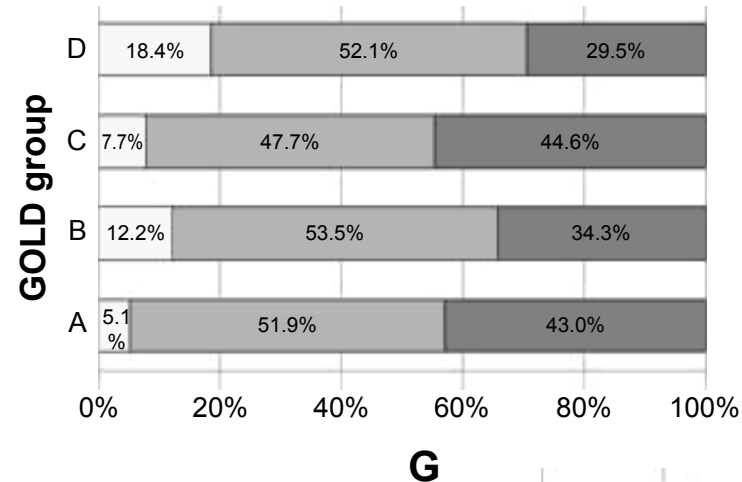

B

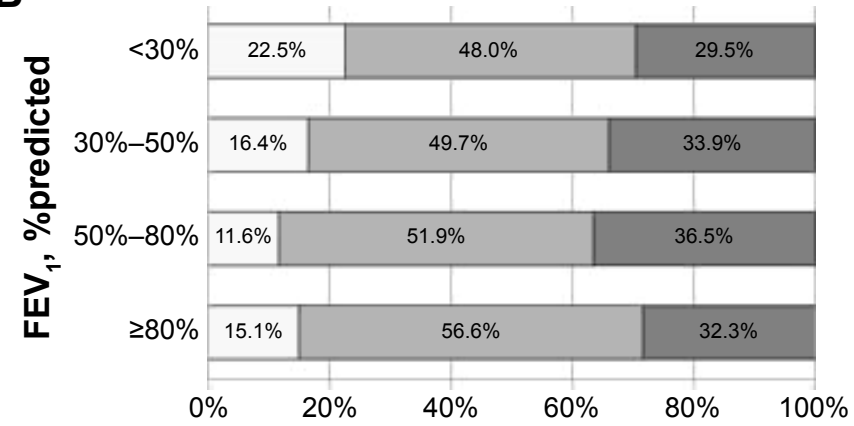

D

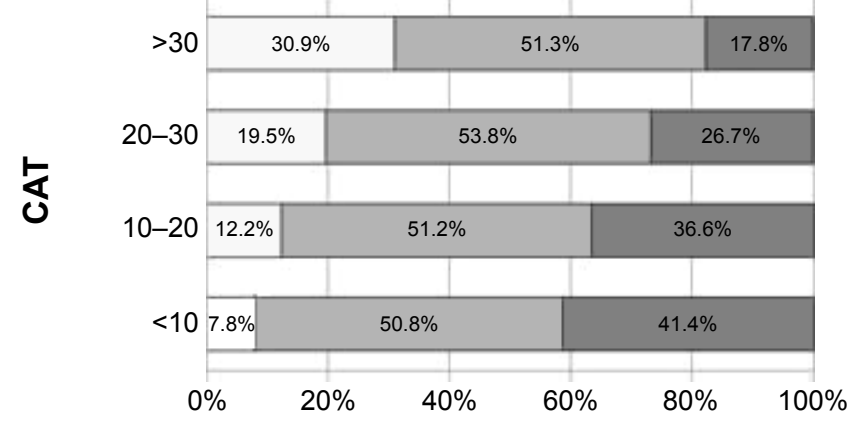

F

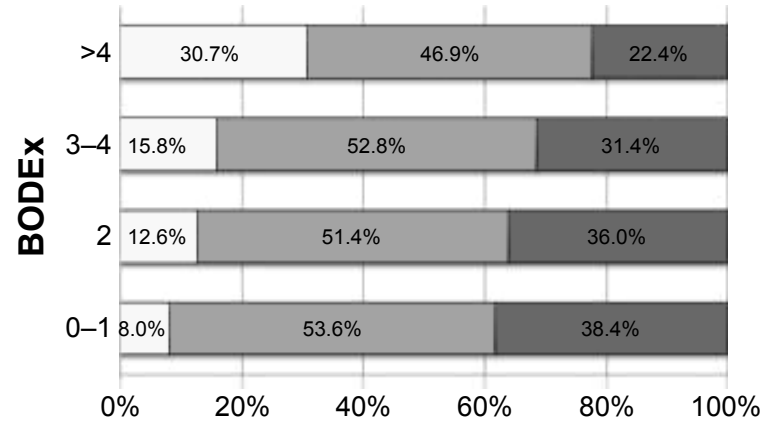

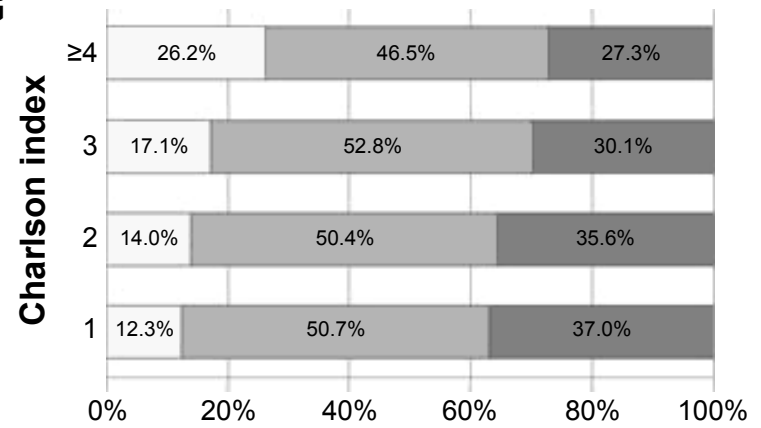

Figure 3 Percentage of patients with self-reported walking time $<30 \mathrm{~min} /$ day ( ), between 30 and $60 \mathrm{~min} / \mathrm{day}(\square)$, and $>60 \mathrm{~min} / \mathrm{day}(\square)$ according to (A) $\mathrm{mMRC}$, (B) FEV \% predicted, (C) COPD admissions in the previous 12 months, (D) CAT, (E) GOLD A-D groups, (F) BODEx index, and (G) Charlson index of comorbidities.

Abbreviations: BODEx, body mass index, airway obstruction, dyspnea, exacerbation; CAT, COPD assessment test; COPD, chronic obstructive pulmonary disease; FEV , forced expiratory volume in the first second; GOLD, Global Initiative for Chronic Obstructive Lung Disease; mMRC, modified Medical Research Council dyspnea scale.

Low physical activity is a marker of poor health outcomes in COPD $, 4,6$ and thus, it is important to detect COPD patients at risk in order to implement specific interventions to prevent inactivity. The use of activity monitors and comprehensive questionnaires to capture physical activity is not feasible in routine clinical practice. Therefore, the utility of a simple clinical measure to predict inactivity in COPD was determined: patients' self-reported daily walking time. The relationship between self-reported walking time and a number of markers of severity routinely used in the clinical management 
Table 3 ORs for the determinants of reduced self-reported walking time

\begin{tabular}{|c|c|c|}
\hline Determinant & $\begin{array}{l}\text { OR for self-reported } \\
\text { walking time }<30 \mathrm{~min} / \text { day } \\
(95 \% \mathrm{Cl})\end{array}$ & $P$-value \\
\hline \multicolumn{3}{|l|}{ mMRC dyspnea score } \\
\hline $0-1$ & 1.00 & \\
\hline 2 & $1.86(1.57-2.20)$ & $<0.00 \mathrm{I}$ \\
\hline 3 & $3.57(2.92-4.37)$ & $<0.001$ \\
\hline 4 & $16.35(11.07-24.13)$ & $<0.00$ I \\
\hline \multicolumn{3}{|l|}{ FEV, levels } \\
\hline$\geqq 80 \%$ predicted & 1.00 & \\
\hline$\geqq 50 \%$ and $<80 \%$ predicted & $0.74(0.53-1.03)$ & 0.080 \\
\hline$\geqq 30 \%$ and $<50 \%$ predicted & I.II (0.80-I.54) & 0.522 \\
\hline$<30 \%$ predicted & $1.64(1.15-2.34)$ & 0.006 \\
\hline \multicolumn{3}{|l|}{ COPD admissions $\pi$} \\
\hline 0 & 1.00 & \\
\hline 1 & $1.41(1.17-1.70)$ & $<0.001$ \\
\hline 2 & $2.47(1.99-3.06)$ & $<0.001$ \\
\hline$>2$ & $3.16(2.53-3.95)$ & $<0.00$ I \\
\hline \multicolumn{3}{|l|}{ CAT } \\
\hline$<10$ & 1.00 & \\
\hline $10-20$ & $1.63(1.14-2.34)$ & 0.008 \\
\hline $20-30$ & $2.85(2.01-4.03)$ & $<0.00 \mathrm{I}$ \\
\hline$>30$ & $5.25(3.52-7.84)$ & $<0.001$ \\
\hline \multicolumn{3}{|l|}{ GOLD groups } \\
\hline A & 1.00 & \\
\hline B & $2.57(1.20-5.47)$ & 0.015 \\
\hline $\mathrm{C}$ & $1.55(0.63-3.85)$ & 0.344 \\
\hline $\mathrm{D}$ & $4.17(2.03-8.56)$ & $<0.001$ \\
\hline \multicolumn{3}{|l|}{ BODEx index } \\
\hline $0-1$ & 1.00 & \\
\hline 2 & $1.52(1.19-1.93)$ & 0.001 \\
\hline $3-4$ & $2.10(1.70-2.60)$ & $<0.00 \mathrm{I}$ \\
\hline$>4$ & $5.08(4.06-6.37)$ & $<0.00$ I \\
\hline \multicolumn{3}{|l|}{ Charlson index } \\
\hline 1 & 1.00 & \\
\hline 2 & I.I5 (0.96-I.37) & 0.131 \\
\hline 3 & $1.47(1.21-1.80)$ & $<0.00$ I \\
\hline$\geqq 4$ & $2.53(2.01-3.18)$ & $<0.001$ \\
\hline
\end{tabular}

Note: "Number of events in the previous 12 months.

Abbreviations: $95 \% \mathrm{Cl}, 95 \%$ confidence interval; BODEx, body mass index, airway obstruction, dyspnea, exacerbation; CAT, COPD assessment test; COPD, chronic obstructive pulmonary disease; $\mathrm{FEV}$, forced expiratory volume in the first second; GOLD, Global Initiative for Chronic Obstructive Lung Disease; mMRC, modified Medical Research Council dyspnea scale; OR, odds ratio.

of patients with COPD. The findings of this study indicate a very consistent association between self-reported walking time and known parameters of COPD severity. Moreover, the results are in line with previous research conducted in this field using objective measures of physical activity, such as pedometers and accelerometers. ${ }^{21-24}$ Therefore, although it is unlikely for the simple question of "on average how many minutes do you walk per day?" to be an accurate measure of physical activity, it may be a useful tool to stratify COPD patients according to their level of physical activity in the clinical setting. Asking about the number of minutes walked per day is inexpensive and not time-consuming and provides important information to help screen patients with low physical activity that can be confirmed by more specific methods. The use of this simple question may increase the awareness of clinicians of the importance of assessing the level of physical activity of the patients with COPD. ${ }^{25}$

In this study, $15 \%$ of the patients were classified as physically inactive (self-reported walking times $<30 \mathrm{~min} /$ day). This percentage might be considered low compared with previous studies quantifying daily walking time in $\mathrm{COPD}^{3}$ but may be due to differences in the characteristics of the COPD patient samples studied, differences in localization and climate that have been reported to affect physical activity, ${ }^{26}$ and the instrument used to capture walking time (eg, self-reported methods have the potential to overestimate the amount of physical activity performed), ${ }^{8,27}$ among others.

In agreement with previous cross-sectional studies using both direct ${ }^{22,23,28}$ and indirect ${ }^{29,30}$ measures of physical activity, a strong association between self-reported walking time and dyspnea measured by the mMRC in the COPD patients was found. Indeed, the mMRC dyspnea score was the best factor to detect patients with lower walking times. COPD is characterized by symptoms of dyspnea, cough, wheeze, and sputum production. ${ }^{1}$ Dyspnea is a particularly dominant symptom in these patients, especially as the disease advances, and usually limits patient mobility. ${ }^{31}$ Indeed, dyspnea is the reason most frequently reported to prevent patients from exercising, ${ }^{29,32}$ further supporting our findings. Although dyspnea measured by mMRC is significantly related to self-reported walking time in this study, different aspects of the impact of the disease are, in fact, measured. Thus, these parameters should not be used interchangeably.

In addition, exacerbations requiring hospitalization within the previous 12 months and comorbidities were related to lower walking times in the patients. Several studies have shown that exacerbations have a negative impact on health outcomes of patients with COPD, impairing lung function, ${ }^{33}$ quality of life, ${ }^{34}$ exercise capacity, ${ }^{35}$ and survival. ${ }^{36}$ Along this line, a fall in daily walking activity following an exacerbation has been reported using pedometry in COPD. ${ }^{21}$ Since bed rest and physical inactivity following exacerbation periods impair skeletal muscle mass and function, ${ }^{37}$ it is not surprising that patients presenting the most severe exacerbations are those who are less active.

Accordingly, other markers of disease severity such as the GOLD A-D classification, the BODEx index, and the 
CAT score which include dyspnea and exacerbation in their calculation were also related to the self-reported walking time in this study. Similar results have been previously reported by using direct measures of physical activity. ${ }^{24}$

This study found airflow limitation to be poorly related to self-reported walking time. Although in some previous studies, $\mathrm{FEV}_{1}$ has shown a weak-moderate association with objectively measured physical activity in patients with COPD, ${ }^{3,22}$ other studies have not observed this relationship. ${ }^{38-40}$ In general, $\mathrm{FEV}_{1}$ is known to explain only a small proportion of the variation in physical activity in subjects with COPD as physical activity is dependent on many factors, including biological, behavioral, social, and environmental factors, among others. ${ }^{7}$ Therefore, we should go beyond $\mathrm{FEV}_{1}$ to better understand how the disease affects the COPD patients.

The main strengths of this study include the large sample of COPD patients with a large variability of disease severity, the different clinical settings in which the patients were tested (primary care and specialized pneumology departments), and the wide range of outcome variables used in this analysis. However, the results of this study may be affected by several limitations. First, an indirect measure of physical activity (patient self-reported walking time) was used, which may be inaccurate, does not quantify the intensity of the activities, and does not capture other physically activities apart from walking. However, walking is the most common way of exercising in the daily life of the elderly. ${ }^{41}$ Second, the associations observed between self-reported walking time and markers of COPD severity do not mean that the question "on average how many minutes do you walk per day?" is a valid measure of physical activity in each individual patient. This is not a formal validation study, as no objective measure was used to compare the results obtained; however, the results support the usefulness of the question to identify a subpopulation of patients who may require interventions to promote physical activity (those with self-reported walking times of $<30 \mathrm{~min} /$ day). Certainly, further studies are needed to validate this question as a reliable measure to identify inactive patients in the clinical setting. In addition, some of the variables tested in these analyses are included in the multidimensional markers of severity, and thus, adjusted multivariate analyses could not be performed. Third, few women were included; therefore, the results cannot be generalized to both the sexes. However, the studies included in this analysis had no exclusion criteria in relation to sex. The lower proportion of women reflects the COPD distribution by sex in this country, as previously reported. ${ }^{42}$ Finally, the cross-sectional nature of the study does not allow us to establish the direction of the observed associations.

\section{Conclusion}

Lower self-reported walking times are related to worse markers of disease severity routinely used in the clinical management of patients with COPD. The use of the question "on average how many minutes do you walk per day?" may provide a simple method for clinicians to identify physically inactive COPD patients.

\section{Acknowledgments}

The FyCEPOC and INSEPOC studies were funded by Laboratorios Esteve SA (Barcelona, Spain). The NEREA study was funded by an unrestricted grant from J Uriach y Compañía SA. The DEPREPOC study was funded by Grupo Ferrer (Barcelona, Spain). The funding bodies have no involvement in the analysis and interpretation of data, the writing of the report, or in the decision to submit the article for publication.

\section{Disclosure}

JM reports personal fees from Boehringer-Ingelheim, Chiesi, Pfizer, AstraZéneca, Rovi, and Teva and has received grants from Boehringer-Ingelheim, Chiesi, Pfizer, and GlaxoSmithKline outside the submitted work. CL reports receiving research grants from the European Commission (Sixth \& Seventh Programme Frameworks and Horizon 2020), Catalan Society of Family Medicine, and Instituto de Salud Carlos III (Spanish Ministry of Health). He also reports having had a grant from the Fundació Jordi Gol i Gurina for a research stage at the University of Cardiff in 2013. CR received grants from Instituto Carlos III (Spanish Government) and Plan Nacional sobre drogas (Spanish Government). The other authors report no conflicts of interest in this work.

\section{References}

1. Vestbo J, Hurd SS, Agustí AG, et al. Global strategy for the diagnosis, management, and prevention of chronic obstructive pulmonary disease: GOLD executive summary. Am J Respir Crit Care Med. 2013; 187:347-365.

2. Agustí AGN, Noguera A, Sauleda J, Sala E, Pons J, Busquets X. Systemic effects of chronic obstructive pulmonary disease. Eur Respir J. 2003;21:347-360.

3. Pitta F, Troosters T, Spruit MA, Probst VS, Decramer M, Gosselink R. Characteristics of physical activities in daily life in chronic obstructive pulmonary disease. Am J Respir Crit Care Med. 2005;171:972-977.

4. Garcia-Aymerich J, Lange P, Benet M, Schnohr P, Antó JM. Regular physical activity reduces hospital admission and mortality in chronic obstructive pulmonary disease: a population based cohort study. Thorax. 2006;61:772-778.

5. Waschki B, Kirsten A, Holz O, et al. Physical activity is the strongest predictor of all-cause mortality in patients with COPD: a prospective cohort study. Chest. 2011;140:331-342.

6. Garcia-Rio F, Rojo B, Casitas R, et al. Prognostic value of the objective measurement of daily physical activity in patients with COPD. Chest. 2012;142:338-346.

7. Watz H, Pitta F, Rochester CL, et al. An official European Respiratory Society statement on physical activity in COPD. Eur Respir J. 2014;44: $1521-1537$. 
8. Pitta F, Troosters T, Probst VS, Spruit MA, Decramer M, Gosselink R. Quantifying physical activity in daily life with questionnaires and motion sensors in COPD. Eur Respir J. 2006;27:1040-1055.

9. Miravitlles M, Soler-Cataluña JJ, Calle M, et al. Spanish COPD Guidelines (GesEPOC): pharmacological treatment of stable COPD. Spanish Society of Pulmonology and Thoracic Surgery. Arch Bronconeumol. 2012;48:247-257.

10. Chodzko-Zajko WJ, Proctor DN, Fiatarone Singh MA, et al. American College of Sports Medicine position stand. Exercise and physical activity for older adults. Med Sci Sports Exerc. 2009;41:1510-1530.

11. Miravitlles M, Naberan K, Cantoni J, Azpeitia A. Socioeconomic status and health-related quality of life of patients with chronic obstructive pulmonary disease. Respiration. 2011;82:402-408.

12. Miravitlles M, Barrecheguren M, Román-Rodríguez M. Frequency and characteristics of different clinical phenotypes of chronic obstructive pulmonary disease. Int J Tuberc Lung Dis. 2015;19:992-998.

13. Miravitlles M, Llor C, de Castellar R, Izquierdo I, Baró E, Donado E. Validation of the COPD severity score for use in primary care: the NEREA study. Eur Respir J. 2009;33:519-527.

14. Miravitlles M, Molina J, Quintano JA, Campuzano A, Pérez J, Roncero C. Factors associated with depression and severe depression in patients with COPD. Respir Med. 2014;108:1615-1625.

15. Charlson M, Szatrowski TP, Peterson J, Gold J. Validation of a combined comorbidity index. J Clin Epidemiol. 1994;47:1245-1251.

16. Bestall JC, Paul EA, Garrod R, Garnham R, Jones PW, Wedzicha JA. Usefulness of the Medical Research Council (MRC) dyspnoea scale as a measure of disability in patients with chronic obstructive pulmonary disease. Thorax. 1999;54:581-586.

17. Jones PW, Harding G, Berry P, Wiklund I, Chen W-H, Kline Leidy N. Development and first validation of the COPD Assessment Test. Eur Respir J. 2009;34:648-654.

18. Celli BR, MacNee W. Standards for the diagnosis and treatment of patients with COPD: a summary of the ATS/ERS position paper. Eur Respir J. 2004;23:932-946.

19. Soler-Cataluña JJ, Martínez-García MA, Sánchez LS, Tordera MP, Sánchez PR. Severe exacerbations and BODE index: two independent risk factors for death in male COPD patients. Respir Med. 2009;103: 692-699.

20. Vorrink SNW, Kort HSM, Troosters T, Lammers J-WJ. Level of daily physical activity in individuals with COPD compared with healthy controls. Respir Res. 2011;12:33.

21. Alahmari AD, Patel ARC, Kowlessar BS, et al. Daily activity during stability and exacerbation of chronic obstructive pulmonary disease. BMC Pulm Med. 2014;14:98.

22. Watz H, Waschki B, Meyer T, Magnussen H. Physical activity in patients with COPD. Eur Respir J. 2009;33:262-272.

23. Hayata A, Minakata Y, Matsunaga K, Nakanishi M, Yamamoto N. Differences in physical activity according to mMRC grade in patients with COPD. Int J COPD. 2016;11:2203-2208.

24. Demeyer H, Gimeno-Santos E, Rabinovich RA, et al. Physical activity characteristics across GOLD quadrants depend on the questionnaire used. PLoS One. 2016;11:e01512555.

25. Moy ML, Gould MK, Liu I-LA, Lee JS, Nguyen HQ. Physical activity assessed in routine care predicts mortality after a COPD hospitalisation. ERJ Open Res. 2016;2:00062-02015.
26. Alahmari AD, Mackay AJ, Patel ARC, et al. Influence of weather and atmospheric pollution on physical activity in patients with COPD. Respir Res. 2015;16:71.

27. Thyregod M, Bodtger U. Coherence between self-reported and objectively measured physical activity in patients with chronic obstructive lung disease: a systematic review. Int J Chron Obstruct Pulmon Dis. 2016;11:2931-2938.

28. DePew ZS, Garofoli AC, Novotny PJ, Benzo RP. Screening for severe physical inactivity in chronic obstructive pulmonary disease: the value of simple measures and the validation of two physical activity questionnaires. Chron Respir Dis. 2013;10:19-27.

29. Katajisto M, Kupiainen H, Rantanen P, et al. Physical inactivity in COPD and increased patient perception of dyspnea. Int J Chron Obstruct Pulmon Dis. 2012;7:743-755.

30. Garcia-Aymerich J, Serra I, Gómez FP, et al. Physical activity and clinical and functional status in COPD. Chest. 2009;136:62-70.

31. Jolley CJ, Moxham J. A physiological model of patient-reported breathlessness during daily activities in COPD. Eur Respir Rev. 2009; 44:1-14.

32. Danilack VA, Weston NA, Richardson CR, Mori DL, Moy ML. Reasons persons with COPD do not walk and relationship with daily step count. COPD J Chronic Obstr Pulm Dis. 2014;11:290-299.

33. Donaldson GC, Seemungal TAR, Bhowmik A, Wedzicha JA. Relationship between exacerbation frequency and lung function decline in chronic obstructive pulmonary disease. Thorax. 2002;57:847-852.

34. Doll H, Miravitlles M. Quality of life in acute exacerbations of chronic bronchitis and chronic obstructive pulmonary disease: a review of the literature. Pharmacoeconomics. 2005;23:345-363.

35. Ramon MA, Gimeno-Santos E, Ferrer J, et al. Hospital admissions and exercise capacity decline in patients with COPD. Eur Respir J. 2014; 43:1018-1027.

36. Soler-Cataluña JJ, Martínez-García MA, Román Sánchez P, Salcedo E, Navarro M, Ochando R. Severe acute exacerbations and mortality in patients with chronic obstructive pulmonary disease. Thorax. 2005;60:925-931.

37. Spruit MA, Gosselink R, Troosters T, et al. Muscle force during an acute exacerbation in hospitalised patients with COPD and its relationship with CXCL8 and IGF-I. Thorax. 2003;58:752-756.

38. Garcia-Aymerich J, Félez MA, Escarrabill J, et al. Physical activity and its determinants in severe chronic obstructive pulmonary disease. Med Sci Sports Exerc. 2004;36:1667-1673.

39. Hernandes NA, Teixeira DDC, Probst VS, et al. Profile of the level of physical activity in the daily lives of patients with COPD in Brazil. J Bras Pneumol. 2009;35:949-956.

40. Pitta F, Takaki MY, Oliveira NH, et al. Relationship between pulmonary function and physical activity in daily life in patients with COPD. Respir Med. 2008;102:1203-1207.

41. Palacios-Ceña D, Alonso-Blanco C, Jiménez-Garcia R, et al. Time trends in leisure time physical activity and physical fitness in elderly people: 20 year follow-up of the Spanish population national health survey (1987-2006). BMC Public Health. 2011;11:799.

42. Miravitlles M, Soriano JB, García-Río F, et al. Prevalence of COPD in Spain: impact of undiagnosed COPD on quality of life and daily life activities. Thorax. 2009;64:863-868.
International Journal of COPD

\section{Publish your work in this journal}

The International Journal of COPD is an international, peer-reviewed journal of therapeutics and pharmacology focusing on concise rapid reporting of clinical studies and reviews in COPD. Special focus is given to the pathophysiological processes underlying the disease, intervention programs, patient focused education, and self management protocols.

\section{Dovepress}

This journal is indexed on PubMed Central, MedLine and CAS. The manuscript management system is completely online and includes a very quick and fair peer-review system, which is all easy to use. Visit http://www.dovepress.com/testimonials.php to read real quotes from published authors. 